\title{
RETRAÇÃO POR SECAGEM, PROPRIEDADES MECÂNICAS, CUSTOS E EMISSÕES EM MATERIAIS DE REPARO A BASE DE CIMENTO
}

\author{
R. OLIVEIRA ${ }^{1 *}$; C. RAMPANELLI ${ }^{1}$; G. PEDRY ${ }^{1}$; E. POSSAN ${ }^{2}$; R. RIZZI ${ }^{3}$ \\ *Rafaela Oliveira: ggorafa@gmail.com \\ ${ }^{1}$ Mestrando(a) de Engenharia Civil, PPGECI, UNILA, Foz do Iguaçu, Brasil. \\ ${ }^{2}$ Professora Doutora, ILATIT, UNILA, Foz do Iguaçu, Brasil. \\ ${ }^{3}$ Professor Doutor, CCET, UNIOESTE, Cascavel, Brasil.
}

\section{RESUMO}

Neste trabalho avalia-se a retração por secagem (ASTM C596, 2018) de seis materiais de reparo a base de cimento (MRBC) para aplicação em estruturas de concreto, proporcionados pelo Modelo de Empacotamento Compressível (MEC). O consumo de cimento variou de 548, 450 e $350 \mathrm{~kg} / \mathrm{m}^{3}$ com adição de polímero EVA $(0 \%$ e $1,5 \%)$, sendo as propriedades mecânicas avaliadas aos 28 dias. $\mathrm{O}$ consumo de cimento apresentou influência significativa na retração, sendo que o menor consumo e a presença de polímero resultaram em menor retração. A otimização do consumo de cimento também reduziu as emissões de $\mathrm{CO}_{2}$. $\mathrm{O}$ emprego do MEC pode ser de interesse para o proporcionamento de $\mathrm{MRBC}$, pois auxilia na redução da retração e emissões com atendimento das propriedades mecânicas.

Palavras-chave: Contração volumétrica; Consumo de cimento; Polímero; Empacotamento de partículas.

\section{ABSTRACT}


In this work it is evaluated the drying shrinkage (ASTM C596, 2018) of six cement-based repair materials (MRBC) for application in concrete structures, designed by the Compressible Packing Model (MEC). Cement content varied from 548, 450 and $350 \mathrm{~kg} / \mathrm{m}^{3}$ with the addition of EVA polymer ( $0 \%$ and $1.5 \%)$, with mechanical properties evaluated at 28 days. The cement content had a significant influence on the shrinkage, and the lower cement content and the presence of polymer resulted in less shrinkage. Optimizing cement content has also reduced $\mathrm{CO}_{2}$ emissions. The use of the MEC may be of interest for the MRBC mix design, as it help to reduce shrinkage and emissions by meeting the mechanical properties.

Key words: Volumetric contraction; Cement content; Polymer; Particle packing.

\section{RESUMEN}

En este trabajo se evalúa la retracción por secado (ASTM C596, 2018) de seis materiales de reparación a base de cemento (MRBC) para aplicación en estructuras de hormigón, proporcionados por el Modelo de Empaque Comprimible (MEC). El consumo de cemento varió de 548,450 y $350 \mathrm{~kg} / \mathrm{m}^{3}$ con la adición de polímero EVA $(0 \%$ y 1,5\%), con propiedades mecánicas evaluadas a los 28 días. El consumo de cemento tuvo una influencia significativa en la retracción, y el menor consumo y la presencia de polímero resultó en una menor retracción. La optimización del consumo de cemento también ha reducido las emisiones de $\mathrm{CO}_{2}$. El uso de MEC puede ser de interés para la provisión de MRBC, ya que ayudan a reducir la retracción y las emisiones al cumplir con las propiedades mecánicas.

Palabras clave: Contracción volumétrica; Consumo de cemento; Polímero; Empaquetamiento de partículas

\section{INTRODUÇÃO}

Recebendo manutenções periódicas, as estruturas de concreto apresentam boa durabilidade (HELENE, 1992). Ainda assim, não é raro apresentarem algum grau de deterioração ao longo da vida útil (GALLETTO, 2005). Dentre os fatores físicos que levam à deterioração do concreto, tem-se a fissuração e o desgaste superficial. A fissuração pode ocorrer por variação volumétrica, carregamento estrutural ou acidental e exposição da estrutura a extremos de temperatura. Já a deterioração por desgaste superficial pode ocorrer devido à cavitação, abrasão e erosão (MEHTA; GERWICK, 1982). Em estruturas hidráulicas, geralmente tem-se a ocorrência de cavitação e erosão, sendo comum o desgaste superficial do concreto pela ação do fluxo de água em alta velocidade, observado nas calhas de vertedouros de usinas hidrelétricas (MEHTA; MONTEIRO, 2014). Considerando que essas manifestações patológicas podem causar desde danos estéticos até danos à capacidade resistente da estrutura (HELENE, 1992), em estruturas hidráulicas que possuem alto valor econômico para serem desativadas ou substituídas, é conveniente o uso de reparos (ROHR, 2018), para reestabelecer propriedades originais dos concretos degradados (GALLETTO, 2005).

Dentre os materiais de reparo, tem-se em geral poliméricos, cimentícios e mistos, que são cimentícios com adição de polímeros (QIAN et al., 2014; MOMAYEZ et al., 2005; LUKOVIC et al., 2012). Os materiais cimentícios, como argamassas e concretos, com e sem adição de polímero, são os mais utilizados para reparos em estruturas de concreto (SOUZA, 2018b). Embora existam outros materiais, os cimentícios são vantajosos, pois possuem propriedades mecânicas semelhantes à maior parte dos substratos de concreto (QIAN et al., 2014; MOMAYEZ et al., 2005; LUKOVIC et al., 2012). 
O material de reparo deve ser compatível com o substrato, apresentar durabilidade, resistência, trabalhabilidade, aderência ao substrato, além de impermeabilidade e baixa retração (SOUZA, 2018a). No entanto, em materiais de reparo com elevado consumo de cimento e aplicados em grandes superfícies, a retração tende a ser elevada. Segundo Mehta e Monteiro (2014), com o aumento da quantidade de cimento tem-se um maior volume de pasta e, consequentemente, menor quantidade de agregados, que são responsáveis por restringir a retração por secagem. Além disso, de acordo com Silva (2016), elementos com elevada área superficial em relação ao volume perdem umidade mais rapidamente para o ambiente, o que eleva a retração por secagem.

Uma das alternativas para a redução do consumo de cimento é a utilização de métodos de empacotamento de partículas (DAMINELI et al., 2017), que buscam reduzir os vazios intragranulares, preenchendo-os com partículas de menores dimensões (BARANHUK, 2014), com objetivo de melhorar a compacidade da mistura (FURNAS, 1931; ROQUIER, 2019; CAMPOS et al., 2020). Assim, no presente trabalho pretende-se avaliar a influência da redução do consumo de cimento, promovida por um método de empacotamento de partículas, na retração por secagem de materiais cimentícios de reparo com e sem presença de polímeros EVA, para aplicação em grandes áreas de reparo de estruturas erodidas. Além disso, pretende-se verificar as possíveis vantagens econômicas e ambientais na redução do consumo de cimento pela utilização de um modelo de empacotamento de partículas.

\section{METODOLOGIA}

Neste estudo foram produzidas misturas variando o consumo de cimento $\left(548,450\right.$ e $\left.350 \mathrm{~kg} / \mathrm{m}^{3}\right)$ e o teor de adição de polímero EVA (0 e 1,5\%), totalizando seis misturas cimentícias (Tabela 1). O proporcionamento base (D1) foi realizado com as proporções definidas por Andrade (2017) e os demais (D2 à D6) foram definidos a partir do Modelo de Empacotamento Compressível (MEC).

Tabela 1. Materiais para a produção de $1 \mathrm{~m}^{3}$ de argamassa para reparo

\begin{tabular}{l|c|c|c|c|c|c}
\hline \multirow{2}{*}{ Material } & \multicolumn{7}{c}{ Misturas } \\
\cline { 2 - 7 } & D1 & D2 & D3 & D4 & D5 & D6 \\
\hline Cimento Portland $\left(\mathrm{kg} / \mathrm{m}^{3}\right)$ & 548,0 & 548,0 & 450,0 & 450,0 & 350,0 & 350,0 \\
\hline Sílica ativa $\left(\mathrm{kg} / \mathrm{m}^{3}\right)$ & 69,0 & 69,0 & 47,0 & 47,0 & 70,0 & 70,0 \\
\hline Areia natural $\left(\mathrm{kg} / \mathrm{m}^{3}\right)$ & 1234,0 & 1234,0 & 1466,0 & 1466,0 & 1570,0 & 1570,0 \\
\hline Aditivo* $(\%)$ & 0,22 & 0,24 & 0,24 & 0,24 & 1,04 & 1,0 \\
\hline Fibra de polipropileno $\left(\mathrm{kg} / \mathrm{m}^{3}\right)$ & 2,20 & 2,20 & 1,80 & 1,80 & 1,40 & 1,40 \\
\hline Polímero EVA*(\%) & $1,5 \%$ & - & $1,5 \%$ & - & $1,5 \%$ & - \\
\hline Água $\left(\mathrm{kg} / \mathrm{m}^{3}\right)$ & 242,0 & 242,0 & 249,0 & 249,0 & 211,4 & 211,4 \\
\hline Fíler calcário $\left(\mathrm{kg} / \mathrm{m}^{3}\right)$ & - & - & 149,0 & 149,0 & 128,0 & 128,0 \\
\hline Água/Ligante & 0,39 & 0,39 & 0,50 & 0,50 & 0,50 & 0,50 \\
\hline Custo $\left(\mathrm{U} \$ \mathrm{~m}^{3}\right)$ & 123,70 & 97,03 & 115,35 & 93,77 & 112,08 & 95,81 \\
\hline
\end{tabular}

*Teor ótimo de aditivo ajustado pelo índice de consistência, em \% sobre massa do cimento.

\subsection{Caracterização dos materiais}

Para reproduzir amostras de argamassas de reparo, foram utilizados os seguintes materiais: cimento Portland CP V, sílica ativa, filer calcário, areia natural de origem quartzosa do rio Paraná, aditivo superplastificante, polímero EVA, fibra de polipropileno e água, caracterizados conforme a Figura 1 e Tabelas 2 a 5 .

Figura 1. Curvas granulométricas dos materiais particulados 


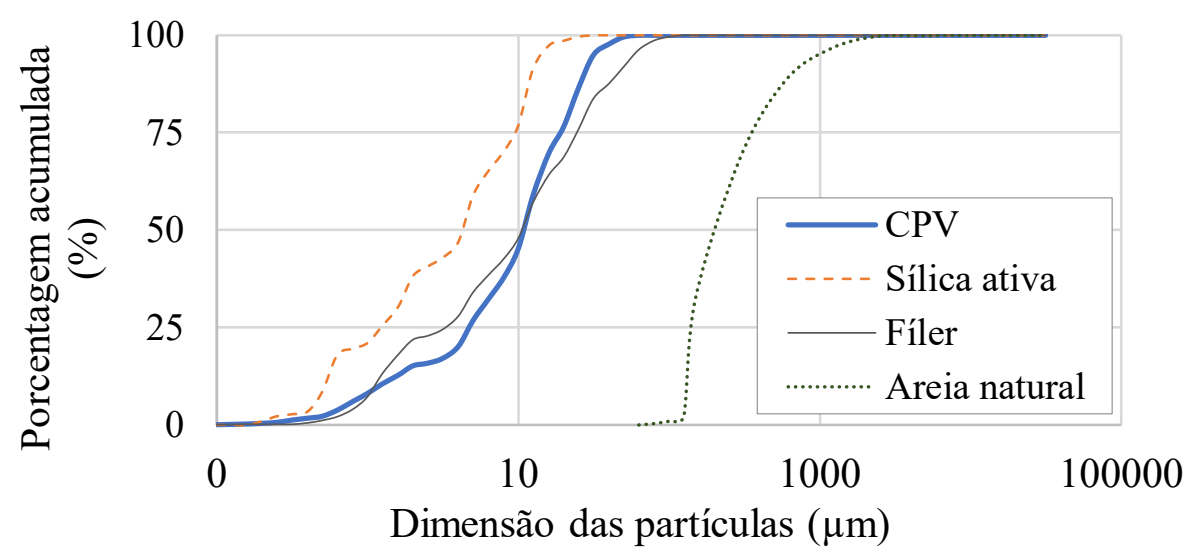

Tabela 2. Resultados dos ensaios de caracterização dos materiais

\begin{tabular}{|c|c|c|c|}
\hline Propriedade & Norma/Procedimento & Material & Resultado \\
\hline \multirow{4}{*}{ Massa específica $\left(\mathrm{g} / \mathrm{cm}^{3}\right)$} & \multirow{3}{*}{ NBR 16605 (2017) } & Cimento CP V ARI & 2,97 \\
\hline & & Sílica ativa & 2,20 \\
\hline & & Fíler calcário & 2,70 \\
\hline & NBR NM 52 (2009) & Areia natural & 2,64 \\
\hline Massa unitária $\left(\mathrm{g} / \mathrm{cm}^{3}\right)$ & NBR NM 45 (2006) & Areia natural & 1,76 \\
\hline \multirow{3}{*}{$\begin{array}{l}\text { Dmed }(\mu m) \text { por } \\
\text { granulometria a laser }\end{array}$} & \multirow{3}{*}{ ISO 13320 (2009) } & Cimento CP V ARI & 12,32 \\
\hline & & Sílica ativa & 0,35 \\
\hline & & Fíler calcário & 11,84 \\
\hline $\operatorname{Dmax}(\mathrm{mm})$ & NBR NM 248 (2003) & Areia natural & 2,36 \\
\hline \multirow{3}{*}{ Demanda de água ${ }^{1)}$} & \multirow{3}{*}{ Formagini (2005) } & Cimento CP V ARI & 0,616 \\
\hline & & Sílica ativa & 0,391 \\
\hline & & Fíler calcário & 0,737 \\
\hline \multirow{3}{*}{$\begin{array}{l}\text { Ponto de saturação do } \\
\text { aditivo }\end{array}$} & \multirow{3}{*}{ Kantro (1980) } & Pasta (cimento + água) & $0,3 \%^{2)}$ \\
\hline & & Pasta (fíler calcário + água) & $0,3 \%{ }^{2)}$ \\
\hline & & Pasta (sílica ativa + água) & $4,0 \%{ }^{2)}$ \\
\hline Teor de sólidos & ASTM E 2550 (2017) & Aditivo & $33 \%$ \\
\hline
\end{tabular}

Tabela 3. Especificações polímero EVA

Propriedades polímero EVA

\begin{tabular}{l|c}
\hline Estado físico & Pó \\
\hline Teor de umidade $\left(\mathrm{g} / \mathrm{cm}^{3}\right)$ & $0,40-0,60$ \\
\hline Teor de material retido \#40 & máximo $10 \%$ \\
\hline pH solução $1 \%$ & $5,0-9,0$ \\
\hline Teor de umidade $(\%)$ & máximo $2,0 \%$ \\
\hline
\end{tabular}

Fonte: Aditex (Fabricante)
Tabela 4. Especificações fibra

\section{Propriedades fibra de polipropileno}

\begin{tabular}{l|c}
\hline Comprimento $(\mathrm{mm})$ & 6 \\
\hline Diâmetro $(\mu \mathrm{m})$ & 18 \\
\hline Seção & Circular \\
\hline Alongamento $(\%)$ & 80 \\
\hline Módulo de Young $(\mathrm{MPa})$ & 3000 \\
\hline Peso específico & 0,91 \\
\hline Resistência à tração $(\mathrm{MPa})$ & 300 \\
\hline
\end{tabular}

Fonte: Maccaferri (Fabricante)

Tabela 5. Composição química por espectrometria de fluorescência de raios-X (FRX)

\begin{tabular}{c|c|c|c|c}
\hline Amostra (\%) & Cimento & Areia natural & Sílica ativa & Fíler calcário \\
\hline $\mathrm{N}_{2} \mathrm{O}$ & 0,4 & 0,12 & 0,33 & - \\
\hline
\end{tabular}




\begin{tabular}{c|c|c|c|c}
\hline $\mathrm{MgO}$ & 3,73 & 0,06 & 0,59 & 5,5 \\
\hline $\mathrm{Al}_{2} \mathrm{O}_{3}$ & 4,24 & 1,45 & 0,31 & 1,3 \\
\hline $\mathrm{SiO}_{2}$ & 16,2 & 94,4 & 92,5 & 5 \\
\hline $\mathrm{P}_{2} \mathrm{O}_{5}$ & 0,19 & 0,05 & 0,21 & $<0,1$ \\
\hline $\mathrm{SO}_{3}$ & 4,14 & 0,03 & 0,19 & 0,1 \\
\hline $\mathrm{K}_{2} \mathrm{O}$ & 1,41 & 1,14 & 1,91 & 0,3 \\
\hline $\mathrm{CaO}$ & 60,6 & 0,18 & 1,53 & 46,3 \\
\hline $\mathrm{TiO}_{2}$ & 0,64 & 0,48 & nd & 0,1 \\
\hline $\mathrm{Fe}_{2} \mathrm{O}_{3}$ & 4,22 & 1,6 & 0,19 & 0,8 \\
\hline $\mathrm{Outros}$ & 0,35 & 0,09 & 0,25 & 0,02 \\
\hline $\mathrm{P.F}$ & 3,86 & 0,4 & 1,98 & 46,3 \\
\hline
\end{tabular}

nd - não detectado; 0,01 - limite de quantificação FRX; P.F = Perda ao Fogo

\subsection{Produção e ensaio das amostras}

Durante a moldagem foram realizados ensaios de flow table de acordo com a NBR 13276 (ABNT, 2016), para ajustar a quantidade de aditivo a ser colocado na mistura, assim como o ensaio de massa específica conforme a NBR 13278 (ABNT, 2005).

Tabela 6. Ensaios no estado fresco

\begin{tabular}{c|l|c|c|c|c|c}
\hline \multicolumn{2}{c|}{$\begin{array}{c}\text { Mistura/ } \\
\text { Dosagem }\end{array}$} & $\begin{array}{c}\text { Aditivo } \\
(\%)\end{array}$ & $\begin{array}{c}\text { Índice de } \\
\text { consistência }(\mathbf{m m})\end{array}$ & \multicolumn{2}{c|}{ Massa específica (g/cm $)$} & Teor de ar \\
\cline { 5 - 6 } & Experimental & Teórica & incorporado (\%) \\
\hline D1 & $548-0 \%$ & 0,22 & 245,10 & 2,34 & 2,25 & $-3,60$ \\
\hline D2 & $548-1,5 \%$ & 0,24 & 243,62 & 2,30 & 2,22 & $-3,30$ \\
\hline D3 & $450-0 \%$ & 0,24 & 243,74 & 2,32 & 2,29 & $-1,45$ \\
\hline D4 & $450-1,5 \%$ & 0,24 & 237,77 & 2,31 & 2,27 & $-1,96$ \\
\hline D5 & $350-0 \%$ & 1,04 & 242,05 & 2,35 & 2,25 & $-4,00$ \\
\hline D6 & $350-1,5 \%$ & 1,00 & 237,65 & 2,34 & 2,23 & $-5,00$ \\
\hline
\end{tabular}

Para o ensaio de retração por secagem, foram produzidos seis corpos de prova prismáticos de $2,5 \mathrm{x}$ 2,5 x 28,5 cm por mistura, totalizando 36 unidades, desmoldados 24 horas após a produção. Os corpos de prova $(\mathrm{CPs})$ foram submetidos à cura úmida por 48 horas após a desmoldagem, depois disso, foram levados para secagem em sala semi-climatizada durante 25 dias, realizando-se a primeira coleta de dados ( 72 horas após a moldagem). As demais leituras do ensaio foram realizadas aos 4, 11, 18 e 122 dias, após os 25 dias de secagem.

Para a realização desse ensaio foram seguidos os procedimentos da norma ASTM C596 (2018). As leituras foram feitas por meio de um dispositivo metálico que possui um relógio comparador. O corpo de prova prismático com pinos metálicos acoplados em suas extremidades foi posicionado sempre na mesma posição no dispositivo metálico, e a leitura exibida no relógio comparador foi anotada. As medidas de comprimento das amostras em cada idade são dadas pela subtração da leitura obtida de uma barra padrão da leitura obtida dos corpos de prova

A retração por secagem foi estimada subtraindo da medida de comprimento inicial, aos 3 dias do corpo de prova, as medidas de comprimento nas idades $32,39,46$ e 150 dias a partir da data de moldagem das amostras. $\mathrm{O}$ esquema de ensaio está ilustrado na Figura 2.

Figura 2. Esquema ensaio de retração por secagem 


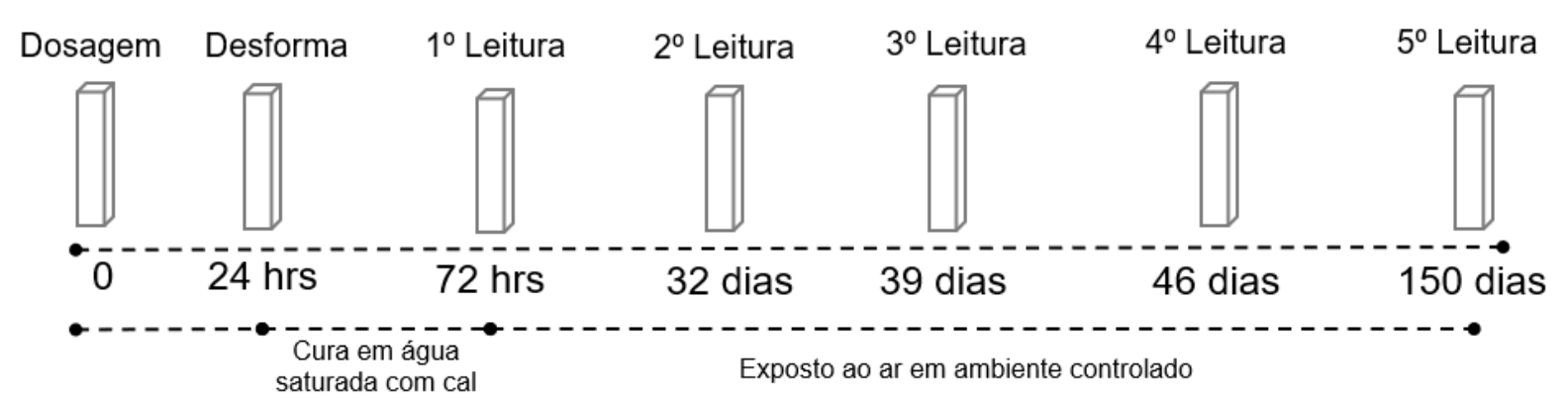

Para o controle tecnológico do material de reparo, foram realizados aos 28 dias ensaios de resistência à compressão, módulo de elasticidade estático e resistência à tração na flexão, de acordo com as normas NBR 5739 (ABNT, 2018), NBR 8522 (ABNT, 2017) e NBR 12142 (ABNT, 2010), respectivamente.

\subsection{Indicadores de desempenho}

\subsubsection{Análise de indicador técnico}

Os resultados foram analisados a partir da verificação da influência das variáveis de controle da pesquisa (presença de polímero e consumo de cimento) na variável de resposta (retração por secagem), por meio da análise gráfica dos dados experimentais. Também se fez a análise de variância (ANOVA) no software Statistica 10.0 avaliando se as variáveis de controle (consumo de cimento e presença de polímeros) exercem influência significativa na retração por secagem (RS) e nas propriedades mecânicas $(f c, f t$ e $E E$ ) considerando o nível de significância de 5\% estipulado na análise.

Os resultados também foram analisados a partir de requisitos de durabilidade do sistema substrato x material de reparo, por meio da verificação das relações ideais entre as propriedades mecânicas do material de reparo e do substrato. Para isso, foram realizadas análises gráficas dos dados experimentais do estudo, em comparação com os dados de três substratos de referência.

\subsubsection{Análise de indicador econômico - Custo do material}

A análise de custo foi realizada por meio de comparações dos valores do $\mathrm{m}^{3}$ das misturas estudadas. Conhecidos os valores $\left(\mathrm{kg} / \mathrm{m}^{3}\right)$ de cada material da mistura (Tabela 1) e seus custos (U\$ $/ \mathrm{kg}$ ) (Tabela 7), calcula-se o valor do $\mathrm{m}^{3}$ de cada mistura desse trabalho. O custo da água foi desconsiderado.

Tabela 7. Informações de compra e custo dos materiais

\begin{tabular}{c|c|c|c}
\hline Material & U\$/kg & Origem do orçamento* & Fornecimento \\
\hline Cimento Portland CP V & 0,10 & Concresuper & Tonelada \\
\hline Sílica ativa & 0,22 & Tecnosil & Sacos $10 \mathrm{~kg}$ \\
\hline Areia natural & 0,01 & Concresuper & Tonelada \\
\hline Aditivo & 3,60 & Mc - Bauchemie & Tambor $210 \mathrm{~kg}$ \\
\hline Fibra de polipropileno & 4,45 & Maccaferri. & Sacos de $100 \mathrm{~g}$ \\
\hline Polímero EVA & 3,20 & Aditex & Sacos $25 \mathrm{~kg}$ \\
\hline Fíler calcário & 0,08 & Calcário Roma & Tonelada \\
\hline
\end{tabular}




\subsubsection{Análise de indicador ambiental - Emissão de $\mathrm{CO}_{2}$}

$\mathrm{Na}$ avaliação de indicador ambiental, foram calculadas as emissões de $\mathrm{CO}_{2}$ das argamassas de reparo. Para isso, estimou-se a quantidade de $\mathrm{CO}_{2}$ liberada na atmosfera devido ao processo de produção dos materiais constituintes da argamassa de reparo, sem considerar o transporte até o local de utilização.

Para determinar as emissões devido à produção do cimento $\left(\mathrm{E}_{\mathrm{c}}\right)$ (Equação 1), multiplica-se as emissões da produção do clínquer $\left(\mathrm{E}_{\text {clín }}\right)$ pela porcentagem presente no cimento $\left(\mathrm{C}_{\mathrm{c}}\right)$ e soma-se ao valor da emissão do consumo de energia elétrica $\left(E_{e e}\right)$ multiplicada pelo fator de emissão (fe).

$$
E_{c}=E_{\text {clin }} x \% C_{c}+E_{e e .} x f e
$$

Para estimar a emissão final de $\mathrm{CO}_{2}$ das argamassas, realizou-se a soma proporcional das emissões dos materiais constituintes da argamassa, ou seja, realizou-se o somatório das emissões típicas desses, multiplicado pelo consumo de cada material, conforme observa-se na Equação 2. Na Tabela 8 estão apresentadas as informações de emissões dos materiais utilizados.

$$
E_{\text {arg }}=E_{\text {cimento }} \times C_{\text {cimento }}+E_{\text {fíler }} \times C_{\text {fíller }}+E_{\text {areia }} \times C_{\text {areia }}
$$

Utilizando as Equações 1 e 2 e as informações da Tabela 8, calculou-se as emissões de $\mathrm{CO}_{2}$ de cada mistura desse trabalho. As emissões das fibras, polímeros e aditivo, foram desconsideradas tendo em vista a dificuldade de encontrar dados confiáveis para as análises. Apesar destes materiais serem empregados em pequenas quantidades, é importante em estudos futuros a consideração das emissões associadas a eles, assim como de outros indicadores ambientais.

Tabela 8. Emissões de $\mathrm{CO}_{2}$ dos materiais constituintes das misturas em estudo

\begin{tabular}{c|c|l|c|c}
\hline Material & Processo & \multicolumn{1}{c|}{ Descrição } & Emissão & Referência \\
\hline \multirow{2}{*}{ Cimento } & \multirow{2}{*}{$\begin{array}{c}\text { Produção } \\
\text { de clínquer }\end{array}$} & $\begin{array}{l}\text { Emissões por calcinação e } \\
\text { queima de combustíveis }\end{array}$ & 866 & GNR PROJECT (2016) \\
\cline { 3 - 5 } & $\begin{array}{c}\text { Energia } \\
\text { elétrica }\end{array}$ & Teor no CP V - ARI (\%) & 90 a 100** & NBR 16697 (2018) \\
\cline { 3 - 5 } & Fator de emissão & 109 & GNR PROJECT \\
\hline $\begin{array}{c}\text { Fíler } \\
\text { Calcário }\end{array}$ & Produção & Emissão $\left(\mathrm{kg} \cdot \mathrm{CO}_{2} / \mathrm{t}\right)$ & 0,08 & MCTIC (2016). \\
\hline Areia & Produção & Emissão $\left(\mathrm{kg} \cdot \mathrm{CO}_{2} / \mathrm{t}\right)$ & 8 & MILLER et al. $(2017)$ \\
\hline Sílica & Resíduo & Emissão $\left(\mathrm{kg} \cdot \mathrm{CO}_{2} / \mathrm{t}\right)$ & 47,84 & RIGO (2019) \\
\hline
\end{tabular}

* A sílica é subproduto da produção de ligas de ferro silício, carbono neutro (zero emissão) **Adotado 95\%

\subsubsection{Avaliação global dos indicadores}

Com a análise conjunta dos indicadores, pode-se selecionar a mistura mais promissora em termos técnicos (retração e propriedades mecânicas), econômicos (custo) e ambientais (emissões de $\mathrm{CO}_{2}$ ).

\section{RESULTADOS}

\subsection{Análise gráfica dos dados experimentais}

Avaliando a Figura 3, percebe-se uma tendência de aumento da retração ao longo do tempo. 
Figura 3. Retração por secagem em função do consumo de cimento

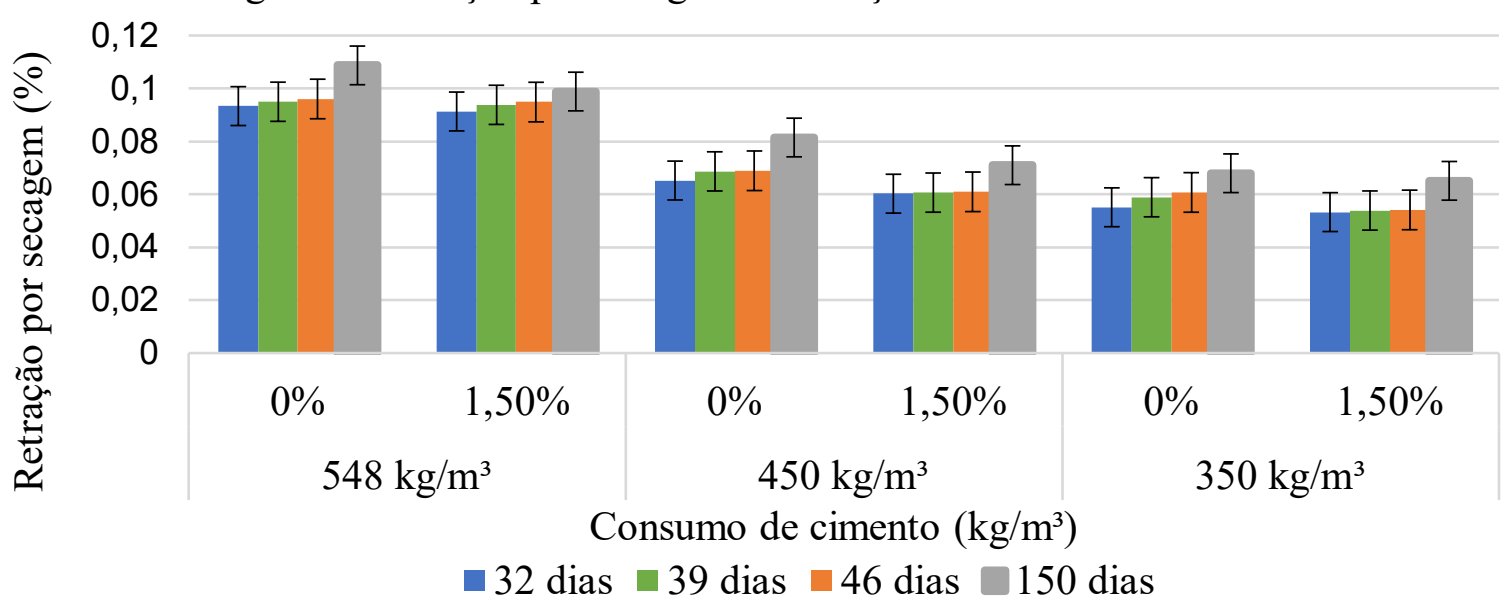

Observou-se que as taxas de retração são maiores para misturas com consumo de cimento mais elevado, em concordância com Mehta e Monteiro (2014). Um consumo de cimento mais alto implica no aumento da quantidade de pasta e assim, a redução da quantidade de agregados. E esses atuam na redução da retração por secagem (MEHTA; MONTEIRO, 2014). A presença de polímero EVA também influenciou na diminuição da retração, em concordância com Weng (2017), que afirma que os polímeros atuam no preenchimento dos poros capilares, diminuindo assim a perda de água e, logo, a retração por secagem. Assim, as misturas de menor consumo de cimento e com presença de polímero apresentaram as menores taxas de retração.

A redução do consumo de cimento de $548 \mathrm{~kg} / \mathrm{m}^{3}$, para $450 \mathrm{~kg} / \mathrm{m}^{3}$ e $350 \mathrm{~kg} / \mathrm{m}^{3}$, levou a uma redução de $25,07 \%$ e 37,49\% respectivamente no valor final de retração aos 150 dias. A adição de polímeros às misturas reduziu o valor final de retração por secagem, em $9,09 \%$ para o consumo $548 \mathrm{~kg} / \mathrm{m}^{3}$, em $12,85 \%$ para o consumo $450 \mathrm{~kg} / \mathrm{m}^{3}$ e em $4,21 \%$ para o consumo de $350 \mathrm{~kg} / \mathrm{m}^{3}$.

\subsection{Análise de variância (ANOVA) - Retração por secagem}

Pela análise de variância (ANOVA), observa-se que apenas o consumo de cimento influencia significativamente a retração por secagem (Figura 4), que é reduzida à medida que o consumo de cimento diminui.

Figura 4. Influência do consumo de cimento na retração por secagem

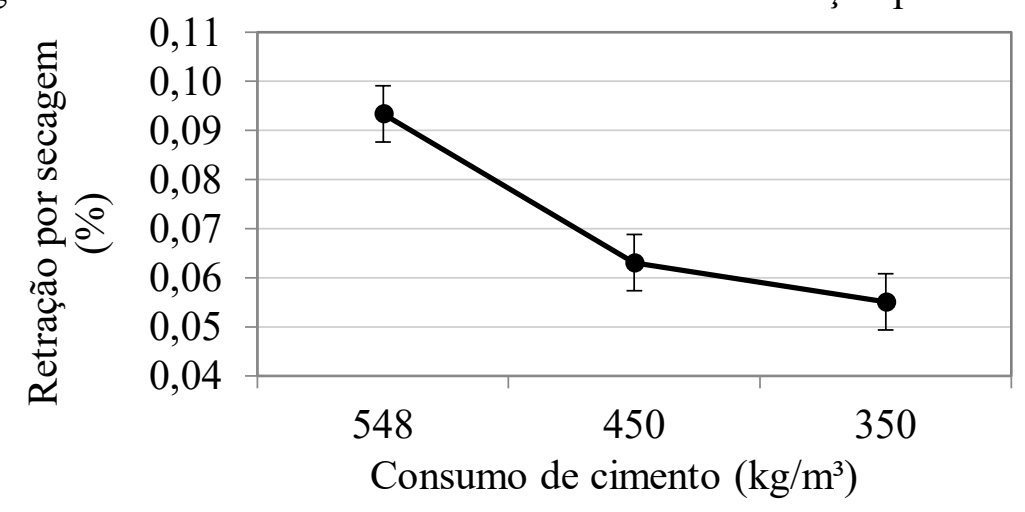

De acordo com a análise gráfica dos dados experimentais, houve redução da retração com o uso de polímeros, ganho que não pode ser desconsiderado apesar da não significância estatística para o intervalo de confiança de $5 \%$ empregado. Assim, a realização de estudos com maiores idades de 
ensaio e outros teores de polímero, para melhor avaliar a significância desses na retração por secagem é recomendada.

\subsection{Análise de variância (ANOVA) - Propriedades mecânicas}

Pela ANOVA, observa-se que o consumo de cimento é significativo para todas as propriedades mecânicas $(f c, f t$ e $E E)$, sendo o único fator de significância para o módulo de elasticidade. Para a resistência à tração e à compressão, os polímeros e a interação entre o consumo de cimento e a idade também apresentaram significância estatística. Para a resistência à compressão, além desses, a idade, a interação da idade com o consumo de cimento e a interação entre idade, consumo de cimento e polímeros, também foram significativos.

\subsection{Análise de requisitos de durabilidade}

Na Tabela 9, são apresentados os valores dos indicadores de desempenho aos 28 dias dos três substratos de referência (19A35, 19B14 e 19B21) para aplicação de cada mistura da pesquisa, bem como os valores de retração final correspondentes. Os dados dos substratos de referência são da calha do vertedouro de Itaipu e foram obtidos de Escobar (2015).

Tabela 9. Comparativo de indicadores de desempenho

\begin{tabular}{|c|c|c|c|c|c|c|c|c|}
\hline \multirow{2}{*}{\multicolumn{3}{|c|}{ Identificação }} & \multicolumn{4}{|c|}{ Propriedades mecânicas aos 28 dias } & \multicolumn{2}{|c|}{ Retração aos 150 dias } \\
\hline & & & \multirow{2}{*}{$\begin{array}{c}\text { fc (MPa) } \\
58,70\end{array}$} & \multirow{2}{*}{\begin{tabular}{|c|} 
Sd \\
-
\end{tabular}} & \multirow{2}{*}{$\begin{array}{c}\mathbf{E E} \text { (GPa) } \\
40,40\end{array}$} & \multirow{2}{*}{$\begin{array}{c}\text { Sd } \\
-\end{array}$} & \multirow{2}{*}{ RS (\%) } & \multirow{2}{*}{ Sd } \\
\hline \multirow{3}{*}{\multicolumn{2}{|c|}{ Substrato* }} & 19A35 & & & & & & \\
\hline & & 19B14 & 57,9 & - & 37,9 & - & \multirow[t]{2}{*}{ - } & \multirow[t]{2}{*}{-} \\
\hline & & 19B21 & 50,5 & - & 31,2 & - & & \\
\hline \multirow{6}{*}{$\begin{array}{c}\text { Materiais } \\
\text { de } \\
\text { reparo }\end{array}$} & D1 & $548-0 \%$ & 60,23 & 1,70 & 34,01 & 1,52 & 0,10871 & 0,09139 \\
\hline & D2 & $548-1,5 \%$ & 60,74 & 2,04 & 30,75 & 4,21 & 0,09883 & 0,06334 \\
\hline & D3 & $450-0 \%$ & 49,04 & 1,27 & 35,58 & 1,61 & 0,08146 & 0,05405 \\
\hline & D4 & $450-1,5 \%$ & 44,28 & 0,78 & 36,23 & 4,18 & 0,07099 & 0,00911 \\
\hline & D5 & $350-0 \%$ & 57,22 & 0,85 & 37,08 & 1,63 & 0,06795 & 0,07657 \\
\hline & D6 & $350-1,5 \%$ & 57,65 & 1,77 & 42,61 & 2,85 & 0,06509 & 0,01810 \\
\hline
\end{tabular}

$\mathrm{S} \overline{\mathrm{d}}=$ desvio padrão; $\mathrm{RS}=$ Retração por secagem; *Os dados do substrato são de Escobar (2015).

Essas propriedades foram avaliadas considerando as relações das propriedades mecânicas entre material de reparo e substrato, para que esse sistema apresente boa durabilidade, indicados na Tabela 10. Ou seja, é desejável que o material de reparo tenha resistência à compressão maior, e módulo de elasticidade similar ao substrato em que será aplicado.

Tabela 10. Requisitos sistema substrato x material de reparo (MR)

\begin{tabular}{c|c}
\hline Propriedade & Relação material de reparo (MR) x Substrato (S) \\
\hline Resistência à compressão (MPa) & $\mathrm{MR}>\mathrm{S}$ \\
\hline Módulo de elasticidade estático (GPa) & $\mathrm{MR} \cong \mathrm{S}$ \\
\hline
\end{tabular}

Fonte: Cusson (2009); Sandström (2010); Lukovic et al., (2012); Vaysburd et al., (2014)

Analisando as Tabelas 9 e 10, percebe-se que as relações ideais para o módulo de elasticidade, não são atendidas para a mistura $548-1,5 \%$ em relação ao substrato 19A35, e para a mistura 350-1,5\%, em relação ao substrato 19B21. 
Para a resistência à compressão, as misturas de $548 \mathrm{~kg} / \mathrm{m}^{3}$ e $350 \mathrm{~kg} / \mathrm{m}^{3}$ (considerando o desvio padrão) atendem às relações ideais para todos os substratos, exceto a mistura de $350-0 \%$ para o substrato 19A35. A mistura de $450 \mathrm{~kg} / \mathrm{m}^{3}-1,5 \%$ não atende aos requisitos de $f c$ para nenhum substrato, e a 450-0\% fica bem próxima de atender apenas para o substrato 19B21 (considerando o desvio padrão). Isso se deve provavelmente a um problema na dosagem dessa mistura (450 $\mathrm{kg} / \mathrm{m}^{3}$ ), pois essa apresentou uma reação água/ligante mais alta que o traço referência (ver Tabela 1) e a quantidade de sílica está bastante reduzida em relação aos demais traços.

Uma maior relação água/ligante implica em perda de resistência (FORMAGINI, 2005), a sílica é um material reativo responsável pelo ganho de resistência em idades mais avançadas, assim a redução do seu teor também acarreta diminuição da resistência (ANDRADE, 2017).

A combinação de propriedades ideais para redução da fissuração em materiais à base de cimento conta com um baixo módulo de elasticidade, alta resistência à tração, elevada fluência e baixa retração (VAYSBURD et al., 2014). Um módulo de elasticidade menor, diminui a magnitude das tensões devido às variações volumétricas inerentes da estrutura (VAYSBURD, 2005). Quanto maior a resistência à tração, menor a chance de a tensão de tração exceder a capacidade do material resistir a esse esforço, provocando fissuras no material (VAYSBURD et al., 2014).

Os módulos de elasticidade encontrados para os materiais de reparo, em geral, foram próximos aos dos substratos, exceto para a mistura 548-1,5\% em relação ao substrato 19A35 e para a mistura $350-1,5 \%$ em relação ao substrato 19B21. As resistências à compressão foram mais altas que as dos substratos, nos materiais de $548 \mathrm{~kg} / \mathrm{m}^{3}$ e $350 \mathrm{~kg} / \mathrm{m}^{3}$ (considerando o desvio padrão), exceto a mistura de $350-0 \%$ para o substrato $19 \mathrm{~A} 35$.

Levando em conta que as misturas de $350 \mathrm{~kg} / \mathrm{m}^{3}$, com e sem polímero, apresentaram valores de retração muito próximos entre si, menores que os das demais misturas (450 e $548 \mathrm{~kg} / \mathrm{m}^{3}$ ), e boas propriedades mecânicas, as misturas com $350 \mathrm{~kg} / \mathrm{m}^{3}$ de cimento poderiam ser as misturas mais otimizadas em termos de propriedades mecânicas.

Contudo, é importante destacar que para a tomada de decisão faz-se necessário avaliar concomitantemente outras propriedades dos materiais de reparo, sobretudo aderência, erosão ou abrasão hidráulica e coeficiente de dilatação térmica.

\subsection{Análise de indicador econômico (Custo do material)}

Analisando o custo apresentado na Tabela 1, nota-se que os materiais mais dispendiosos são o cimento e o polímero. Nas misturas sem polímero, ao reduzir o consumo de cimento para $450 \mathrm{~kg} / \mathrm{m}^{3}$ e $350 \mathrm{~kg} / \mathrm{m}^{3}$, houve uma redução do custo de 3,35\% e 1,26\% respectivamente em relação ao consumo de $548 \mathrm{~kg} / \mathrm{m}^{3}$. Nas misturas com polímero, ao reduzir o consumo de cimento para 450 $\mathrm{kg} / \mathrm{m}^{3}$ e $350 \mathrm{~kg} / \mathrm{m}^{3}$ houve uma redução do custo de $6,75 \%$ e $9,39 \%$ respectivamente em relação ao consumo de $548 \mathrm{~kg} / \mathrm{m}^{3}$.

Ao adicionar polímeros às misturas, houve um aumento no custo de $27,48 \%, 23,00 \%$ e $16,98 \%$ para os consumos de cimento de $548 \mathrm{~kg} / \mathrm{m}^{3}, 450 \mathrm{~kg} / \mathrm{m}^{3}$ e $350 \mathrm{~kg} / \mathrm{m}^{3}$ respectivamente.

Observa-se que a redução do custo do traço referência $\left(548 \mathrm{~kg} / \mathrm{m}^{3}\right)$ para o traço de $350 \mathrm{~kg} / \mathrm{m}^{3}$ foi pequena, uma vez que para compensar a redução do consumo de cimento, adicionou-se fíler calcário e aumentou-se a quantidade de areia e aditivo, o que elevou o custo. Contudo, tem-se ganhos em relação à redução da retração, o que é desejável do ponto de vista técnico.

A adição de polímeros às misturas elevou consideravelmente o custo e o ganho em relação à redução de retração foi pequeno. Assim, estudos devem ser conduzidos para determinar o teor ideal de polímero a ser adicionado, a fim de garantir os benefícios da redução de retração, sem elevar tanto o custo. 


\subsection{Análise de indicador ambiental (Emissão de $\left.\mathrm{CO}_{2}\right)$}

Os resultados das emissões de $\mathrm{CO}_{2}$ associadas à produção de cada mistura estão apresentados na Figura 5. Nota-se que ao reduzir o consumo de cimento para $450 \mathrm{~kg} / \mathrm{m}^{3}$ e $350 \mathrm{~kg} / \mathrm{m}^{3}$ houve uma redução das emissões de $\mathrm{CO}_{2}$ de $13,44 \%$ e $28,66 \%$ respectivamente em relação ao consumo de $548 \mathrm{~kg} / \mathrm{m}^{3}$. Como as emissões de alguns materiais foram desconsideradas, não houve diferença no valor das emissões pela presença de polímero.

\subsection{Avaliação global dos indicadores considerados}

Na Figura 5, é possível observar as relações entre as variáveis de controle (consumo de cimento e presença de polímeros), a variável de resposta (retração por secagem) e os parâmetros de análise (propriedades mecânicas $(f c, f t$ e $E E)$, custos e emissões).

Figura 5. Avaliação global dos indicadores considerados

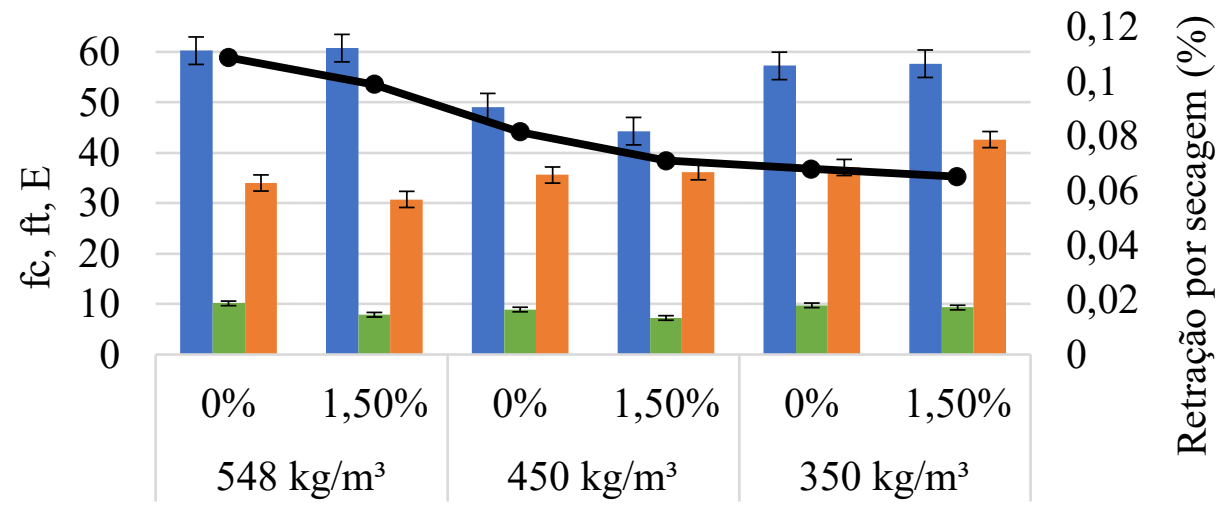

Consumo de cimento $\left(\mathrm{kg} / \mathrm{m}^{3}\right)$

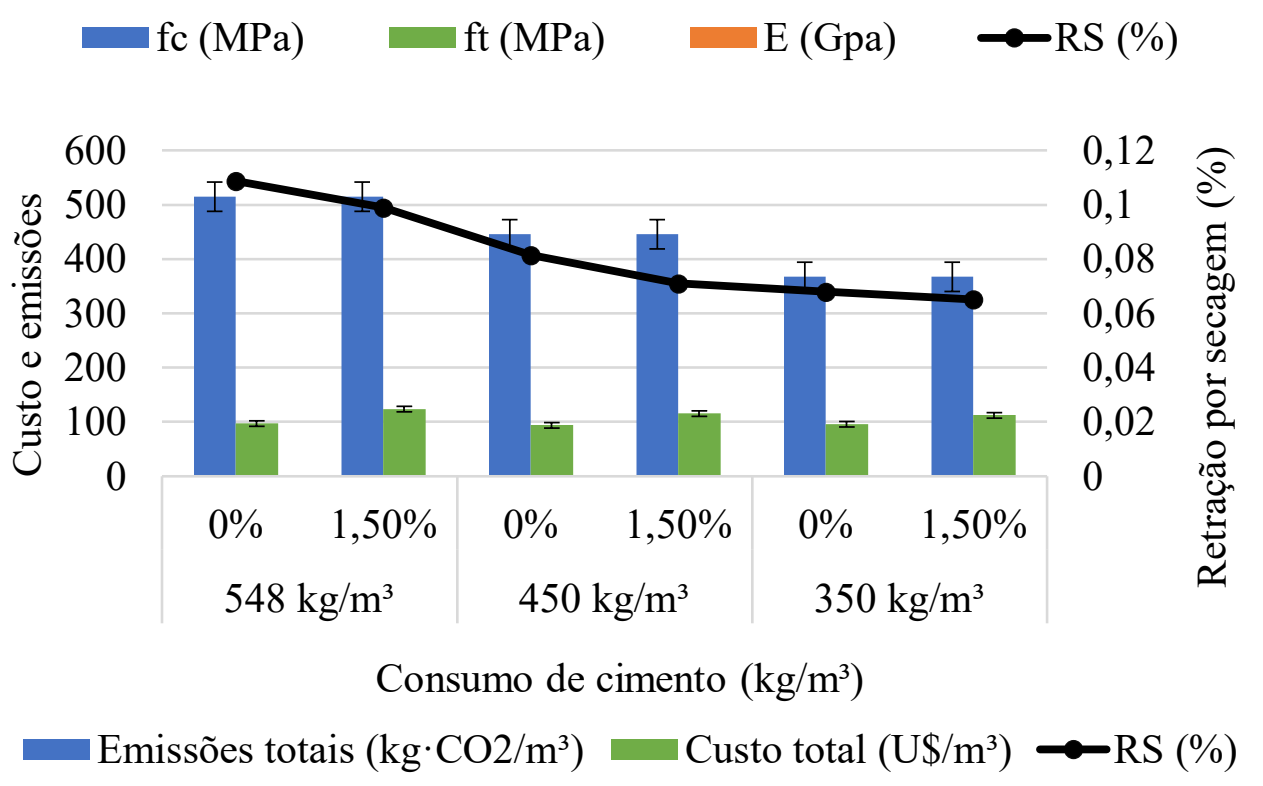

Fazendo uma avaliação conjunta de todos os aspectos de análise, a mistura de consumo de cimento de $350 \mathrm{~kg} / \mathrm{m}^{3}$, sem presença de polímeros (D5), pode ser a mais adequada do ponto de vista técnico, econômico e ambiental. Uma vez que apresentou a menor taxa de retração por secagem, atendeu 
às relações das propriedades mecânicas entre material de reparo e substrato para que esse sistema apresente boa durabilidade, proporcionou a maior redução $(28,66 \%)$ das emissões de $\mathrm{CO}_{2} \mathrm{em}$ relação ao traço de referência, e apesar de pequena, gerou também uma redução de custo de 1,26\% em relação a mistura de referência.

\section{CONCLUSÃO}

Tendo em vista o objetivo de avaliar a retração por secagem, propriedades mecânicas, custos e emissões em materiais cimentícios de reparo, com e sem adição de polímero EVA, proporcionados pelo MEC e analisando os resultados obtidos, chegou-se às seguintes conclusões:

a) A redução do consumo de cimento proporcionada pela utilização do MEC apresenta influência estatística significativa na retração por secagem, apresentando uma tendência de diminuição da retração por secagem conforme diminui-se o consumo de cimento.

b) A presença de polímeros também influenciou na retração por secagem, uma vez que as misturas com polímero apresentaram menores valores de retração, no entanto, não se observou significância estatística. Logo, mais estudos devem ser realizados para determinar o teor adequado de utilização deste, pois apesar do efeito positivo do ponto de vista técnico (redução da retração), do ponto de vista econômico, a presença de polímero elevou muito o custo do material de reparo.

c) Os ganhos da redução do consumo de cimento proporcionada pela utilização do MEC, em termos econômicos, foram pequenos, uma vez que para compensar a redução do consumo de cimento, outros materiais tiveram que ser adicionados, o que elevou o custo global da mistura. Nesse sentido, avaliações econômicas devem ser realizadas concomitantemente ao processo de dosagem para que se possa obter uma mistura com consumo de cimento otimizado e com redução mais significativa dos custos. No entanto no que diz respeito a vantagens ambientais, a otimização do consumo de cimento levou a uma redução nos valores de emissões de $\mathrm{CO}_{2}$.

d) Com base nos resultados desse estudo, a mistura que se mostrou mais promissora, considerando todos os aspectos de análise (desempenho, custos e emissões), foi a de consumo de cimento de $350 \mathrm{~kg} / \mathrm{m}^{3}$, sem presença de polímeros (D5). Pois, atendeu aos requisitos de durabilidade e proporcionou redução das emissões de $\mathrm{CO}_{2}$ e custo. Entretanto, mais estudos devem ser conduzidos para determinar o teor adequado de utilização de polímeros, para que seja possível aproveitar seus benefícios quanto à redução de retração sem onerar.

Para estudos futuros, sugere-se a realização de um projeto experimental com estudo de mais teores de polímero, que levem em conta outras propriedades relevantes para o desempenho dos materiais de reparo (aderência, contração térmica, erosão e abrasão hidráulica) e com avaliações de custo em paralelo ao processo de dosagem.

\section{AGRADECIMENTOS}

À Fundação Parque Tecnológico de Itaipu, pelo financiamento do projeto de pesquisa que originou este trabalho e pela bolsa de estudos. À Itaipu Binacional, à Universidade Estadual do Oeste do Paraná e à Concresuper de Cascavel, pela colaboração para os ensaios da pesquisa. E à Votorantin e MC-bauchemie pela doação de materiais. 


\section{REFERÊNCIAS}

AMERICAN SOCIETY FOR TESTING AND MATERIALS. (2018). ASTM C596 Standard Test Method for Drying Shrinkage of Mortar Containing Hydraulic Cement. West Conshohocken. https://dx.doi.org/10.1520/C0596-18

ANDRADE, W. P. Procedimento de reparos de concretos. 2017. [Documento restrito, cedido pelo autor].

ASSOCIAÇÃO BRASILEIRA DE NORMAS TÉCNICAS. (2018). NBR 5739: Concreto-Ensaios de compressão de corpos de prova cilíndricos. Rio de Janeiro.

ASSOCIAÇÃO BRASILEIRA DE NORMAS TÉCNICAS. (2017). NBR 8522: Determinação do módulo estático de elasticidade à compressão. Rio de Janeiro.

ASSOCIAÇÃO BRASILEIRA DE NORMAS TÉCNICAS. (2019). NBR 11768-3: Aditivos químicos para concreto de cimento Portland Parte 3: Ensaios de caracterização. Rio de Janeiro.

ASSOCIAÇÃO BRASILEIRA DE NORMAS TÉCNICAS. (2010). NBR 12142: Concreto Determinação da resistência à tração na flexão de corpos de prova prismáticos. Rio de Janeiro.

ASSOCIAÇÃO BRASILEIRA DE NORMAS TÉCNICAS. (2016). NBR 13276: Argamassa para assentamento e revestimento de paredes e tetos - Determinação do índice de consistência. Rio de Janeiro.

ASSOCIAÇÃO BRASILEIRA DE NORMAS TÉCNICAS. (2005). NBR 13278: Argamassa para assentamento e revestimento de paredes e tetos - Determinação da densidade de massa e do teor de ar incorporado. Rio de Janeiro.

ASSOCIAÇÃO BRASILEIRA DE NORMAS TÉCNICAS. (2016). NBR 16137: Ensaios não destrutivos - Identificação de materiais por teste por pontos, espectrometria por fluorescência de raios $X$ e espectrometria por emissão óptica. Rio de Janeiro.

ASSOCIAÇÃO BRASILEIRA DE NORMAS TÉCNICAS. (2018). NBR 16697: Cimento Portland - Requisitos. Rio de Janeiro.

BARANHUK, A. D. (2014), "Análise da influência do empacotamento dos agregados na porosidade do concreto", Trabalho de Conclusão de Curso, Universidade Tecnológica Federal do Paraná, p. 86.

CAMPOS, H.; KLEIN, N.; FILHO, J. M. (2020), Proposed mix design method for sustainable high-strength concrete using particle packing optimization. Journal of Cleaner Production, Elsevier, v.265. https://doi.org/10.1016/j.jclepro.2020.121907

CUSSON, D. (2009), Durability of concrete repaired concrete structures. Failure, Distress and Repair of Concrete Structure, pp.297-321. 
DAMINELI, B. L.; PILEGGI, R. G.; JOHN, V. M. (2017), Influence of packing and dispersion of particles on the cement content of concretes. Revista IBRACON de Estruturas e Materiais, SciELO Brasil. 10(5):998-1024. https://doi.org/10.1590/S1983-41952017000500004

ESCOBAR, C. T. M. (2015), "Estudo de materiais de reparo para a calha esquerda do vertedouro da usina hidrelétrica de Itaipu”, Trabalho de Conclusão de Curso, Universidade Federal de Uberlândia.

FORMAGINI, S. (2005), "Dosagem Científica e Caracterização Mecânica de Concretos de Altíssimo Desempenho", Tese de Doutorado em Engenharia Civil, Universidade Federal do Rio de Janeiro, p. 285.

FURNAS, C. (1931), Grading aggregates-i.-mathematical relations for beds of broken solids of maximum density. Industrial \& Engineering Chemistry, ACS Publications. 23(9):1052-1058. https://doi.org/10.1021/ie50261a017

GAlletTO, A. (2005), "Reparo de Estruturas de Concreto: Contribuição ao Estudo da Aderência”, Dissertação de Mestrado, Universidade Estadual de Campinas, p. 159.

HELENE, P. R. L. (1992), Manual para reparo, reforço e proteção de estruturas de concreto. $2^{\mathrm{a}}$. Ed. São Paulo: Pini.

KANTRO, D. L. (1980), Influence of water-reducing admixtures on properties of cement paste a miniature slump test. Cement, Concrete and Aggregates, ASTM International. 2(2): 95-102. https://doi.org/10.1520/CCA10190J

KULAKOWSKI, M. P. (2002), "Contribuição ao Estudo da Carbonatação em Concretos e Argamassas Compostos com Adição de Sílica Ativa”, Tese de Doutorado em Engenharia, Universidade Federal do Rio Grande do Sul, p. 199.

LUKOVIC, M.; YE, G.; VAN BREUGEL, K. (2012). "Reliable concrete repair: A critical review”, in: 14th International Conference Structural Faults and Repair, Edinburgh, Scotland, UK, pp. 3-5.

MEHTA, P. K.; GERWICK Jr., B. C. (1982), Cracking-Corrosion Interaction in Concrete Exposed to Marine Environment. Concrete International. 4(10) 45:51.

MEHTA, P. K.; MONTEIRO, P. J. M. (2014), "Concreto: microestrutura, propriedades e materiais". IBRACON, 2. ed., Porto Alegre, Brasil, p. 912.

MILlER, S. A.; JOHN, V. M.; PACCA, S. A.; HORVATH, A. (2018) Carbon dioxide reduction potential in the global cement industry by 2050. Cement and Concrete Research. 114 (November 2016):115-124.

MINISTÉRIO DA CIÊNCIA, TECNOLOGIA, INOVAÇÃO E COMUNICAÇÕES - MCTIC.

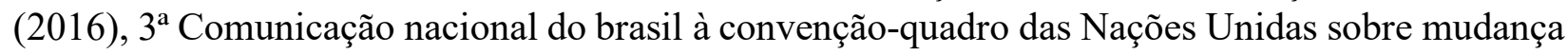
do clima. Secretaria e Políticas e Programas de Pesquisa e Desenvolvimento. Brasília. 
MOMAYEZ, A; EHSANI, M. R; RAMEZANIANPOUR, A. A; RAJAIE, H. (2005), Comparison of methods for evaluating bond strength between concrete substrate and repair materials. Cement and Concrete Research. 35(4) 748:757. https://doi.org/10.1016/j.cemconres.2004.05.027

QIAN, J.; YOU, C.; WANG, Q.; WANG, H.; JA, X. (2014), A method for assessing bond performance of cement-based repair materials. Construction and Building Materials. 68(15) 307:313. https://doi.org/10.1016/j.conbuildmat.2014.06.048

RIGO, E. (2019), “Avaliação da captura de $\mathrm{CO}_{2}$ devido à carbonatação de concretos com resíduos de construção de demolição”, Dissertação de Mestrado, Universidade Federal da Integração Latino Americana, p. 59.

ROHR, N. G. (2018), “Análise do desempenho de argamassa de reparo com adição de fibra de polipropileno submetida à erosão hidráulica”, Trabalho de Conclusão de Curso, Universidade Estadual do Oeste do Paraná, p. 75.

ROQUIER, G. (2019), A theoretical packing density model (tpdm) for ordered and disordered packings. Powder Technology, Elsevier. 344(15) 343:362. https://doi.org/10.1016/j.powtec.20 18.12 .033

SANDSTRÖM, T. (2010), "Durability of concrete hydropower structures when repaired with concrete overlays", Tese de Doutorado, Luleå Tekniska Universitet.

SILVA, L. M. B. da. (2016), "Influência do carregamento precoce na retração por secagem do concreto", Tese de Doutorado, Universidade Federal do Rio Grande do Sul, p. 393.

SOUZA, K. L. B. de. (2018a), “Análise numérica da influência do material de reparação em vigas de concreto armado recuperadas", Dissertação de Mestrado, Universidade do Estado do Rio de Janeiro, p. 196.

SOUZA, M. H de. (2018b), “Análise De Argamassas De Reparo De Base Polimérica”, Dissertação de Mestrado, Universidade Estadual de Maringá, p. 138.

VAYSBURD, A. M.; BISSONNETTE, B.; FAY, K. F. von., (2014), Compatibility issues in design and implementation of concrete repairs and overlays. US Department of the Interior, Bureau of Reclamation, Technical Service. 39(87) 126:136.

VAYSBURD, A. M. (2005), Repairing concrete: random thoughts on concrete ills and treatment prescriptions. International Journal of Materials and Product Technology, Inderscience Publishers. 23(3-4) 164:176. https://doi.org/10.1504/IJMPT.2005.007725

WBCDS. GNR Project. Weighted average excluding $\mathrm{CO}_{2}$ from on-site power generation Grey clinker, 2016b. Disponível em: < https://www.wbcsdcement.org/GNR-2016. Acesso em: $30 / 10 / 2020$

WENG, T-L. (2017), Evaluation of Cementitious Repair Mortars Modified with Polymers. Advances in Mechanical Engineering. 9(1) 1:7. https://doi.org/10.1177/1687814016688584 